\section{Splenic abscess due to Salmonella enteritidis}

\author{
Hatice Çabadak, ${ }^{1}$ Ayşe Erbay, ${ }^{2}$ \\ Kerem Karaman, ${ }^{3}$ Süha Şen, ${ }^{1}$ \\ Yasemin Tezer-Tekçe ${ }^{1}$
}

'Department of Infectious Diseases and Clinical Microbiology, Türkiye Yüksek İhtisas Education and Research Hospital, Ankara; 'Department of Infectious Diseases and Clinical Microbiology, Bozok University, Faculty of Medicine, Yozgat; ${ }^{3}$ Department of Gastroenterological Surgery, Türkiye Yüksek İhtisas Education and Research Hospital, Ankara, Turkey

\section{Abstract}

Splenic abscess is a very rare complication of non-typhoidal Salmonella infections. We report a case of splenic abscess caused by Salmonella enteritidis. The patient is a 63 -year-old woman with diabetes mellitus and underwent splenectomy. This case suggests that the patients with comorbities are at increased risk for invasive infections in non-typhoidal Salmonella infections.

\section{Introduction}

Nontyphoidal salmonella species are important food borne pathogens and acute gastroenteritis is the most common clinical manifestation accounting for about $70 \%$ of cases. ${ }^{1,2}$ Approximately 5\% of individuals with gastrointestinal illness caused by nontyphoidal salmonella will develop bacteraemia. ${ }^{2}$ Localized Salmonella infections frequently occur during bacteraemia. ${ }^{1}$ Splenic abscess is a very rare complication of nontyphoidal Salmonella infections since the presence of antibiotics. ${ }^{3}$

Here, we report a case of splenic abscess due to Salmonella enteritidis.

\section{Case Report}

A 63-year-old woman from eastern part of Turkey was admitted with the complaint of back pain, vomiting and nausea since 20 days. She had diabetes mellitus and hypertension. Physical examination was normal. Laboratory findings were as follows: white blood cell (WBC) count was $14670 / \mathrm{mm}^{3}$
(88.9\% polymorphonuclear cells), haemoglobin $9.5 \mathrm{~g} / \mathrm{dL}$, platelet count $183000 / \mathrm{mm}^{3}$, erythrocyte sedimentation rate $76 \mathrm{~mm} / \mathrm{h}$, and Creactive protein (CRP) $58 \mathrm{mg} / \mathrm{dL}$ (normal value $<5 \mathrm{mg} / \mathrm{L}$ ). Liver and renal function tests were within normal limits. Blood and urine cultures showed no growth.

Chest X-ray was normal. An abdominal ultrasound revealed a hypoechogenic cystic structure with a diameter of $61 \times 72 \mathrm{~mm}$ in the upper part of the spleen with calcifications (Figure 1). Computed tomographic scan of the abdomen showed splenic abscess. The patient underwent an exploratory laparotomy and splenectomy was performed. Salmonella enteritidis was yielded from culture of the samples of the abscess obtained during the operation. It was sensitive to ampicillin, cotrimoxazole, cephalosporins of third generation, and ciprofloxacin.

After isolation of the $S$. enteritidis from abscess, the patient was questioned in detail, it was learned that the patient had diarrhoea and fever existed 2 days and recovered without antibiotic treatment one month ago. Ciprofloxacin was administered $500 \mathrm{mg}$ bid p.o. for 10 days postoperatively. The patient recovered well after surgery. There were no recurrent symptoms during the follow up.

\section{Discussion}

The usual clinical presentation of nontyphoidal salmonella infection is self-limited gastroenteritis, however bacteraemia and focal extraintestinal infections may occur. ${ }^{4}$ Risk of bacteraemia and focal extraintestinal infections are high in individuals with comorbidities such as malignancy, human immunodeficiency virus (HIV), diabetes mellitus, and patients receiving immunosuppressive therapy. Invasive nontyphoidal Salmonellae disease is a major cause of mortality in African children and HIV-infected African adults. ${ }^{5,6}$ Any tissue or organ may be seeded hematogenously by nontyphoidal salmonella and may form a local infection, become obvious months or even years after the initial bacteraemia producing characteristic clinical syndromes. ${ }^{2,7}$ Some serovars of Salmonella show a higher tendency for causing bacteraemia and these serovars differ in different countries. Non-typhoidal salmonella serovars $S$. typhimurium and $S$. enteritidis are cause of invasive disease in industrialized countries, also they are predominant in African region. ${ }^{5,6} S$. enteritidis had the highest blood invasiveness among non-typhoidal salmonella species in Malaysia. ${ }^{8}$ Our patient had diabetes mellitus and probably $S$. enteri-
Correspondence: Ayse Erbay, Bozok University, Faculty of Medicine, Department of Infectious Diseases and Clinical Microbiology, Adnan Menderes Bulvarı No:190 Yozgat, Turkey.

Tel. +90.533 .576 .7096 - Fax: +90.312 .430 .5393 .

E-mail: ayseerbay@gmail.com

Key words: Salmonella enteritidis, spleen, abscess.

Conflict of interest: the authors report no conflicts of interest.

Received for publication: 9 August 2011.

Revision received: 15 December 2011.

Accepted for publication: 18 December 2011.

This work is licensed under a Creative Commons Attribution NonCommercial 3.0 License (CC BYNC 3.0).

(C) Copyright H. Çabadak et al., 2012

Licensee PAGEPress, Italy

Infectious Disease Reports 2012; 4:e4

doi:10.4081/idr.2012.e4

tidis bacteraemia occurred during the course of diarrhoea one month ago which lead to bacterial seeding in the spleen.

Antibiotic treatment for patients with mild to moderate gastroenteritis due to nontyphoidal salmonella is not indicated in healthy adults. However antimicrobial therapy should be initiated for patients who are severely ill and for patients with risk factors for extraintestinal spread of infection. ${ }^{2}$

Splenic abscess is a rare complication of Salmonella infections. However, salmonella has been isolated in 11-15\% for patients with splenic abscesses. ${ }^{9}$ The symptoms of splenic abscess are usually nonspecific The most frequent symptoms and signs are fever, abdominal pain and tenderness over left upper quadrant, splenomegaly, leucocytosis, and left lower chest abnormalities. ${ }^{10}$ Our patient had back pain, vomiting, nausea and leucocytosis which were not specific for splenic abscess.

Computed tomography remains the gold standard and the most sensitive tool for the definitive diagnosis of splenic abscess. ${ }^{10}$ Ultrasonography is a noninvasive, cheap and effective method for detection of splenic abscess. Ultrasonography has $76 \%$, CT has $96 \%$ sensitivity for the detection of abdominal masses. ${ }^{11}$ In our patient, diagnosis was confirmed with CT.

At present, splenectomy is the gold standard for treatment while ultrasound- or CTassisted percutaneous drainage and antimicrobial therapy can be considered as therapeutic alternatives especially in the presence of an isolated abscess. ${ }^{12}$ We preferred splenectomy for treatment as the causative 


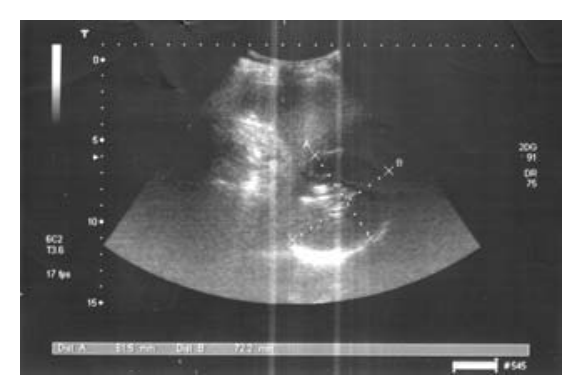

Figure 1. Ultrasound of the abdomen shows a hypoechogenic cystic structure in spleen.

microorganism was not known initially.

In conclusion, although non-typhoidal Salmonella gastroenteritis is rarely resulted with splenic abscess, patients with comorbities are at increased risk. The treatment of splenic abscess includes antibiotic treatment and surgery. Splenectomy is still the most accepted standard surgical treatment of a splenic abscess.

\section{References}

1. Vidal JE, da Silva PR, Schiavon Nogueira R, et al. Liver abscess due to Salmonella enteritidis in a returned traveler with HIV infection: case report and review of the literature. Rev Inst Med trop S Paulo 2003;45:115-7.

2. Hohmann EL. Nontyphoidal salmonellosis. Clin Infect Dis 2001;32:263-9.

3. De Greef E, Hoffman I, Topal B, et al. Partial laparoscopic splenectomy for splenic abscess because of Salmonella infection: a case report. J Pediatr Surg 2008;43:E35-8.

4. Galanakis E, Bitsori M, Maraki S, et al. Invasive non-typhoidal salmonellosis in immunocompetent infants and children. Int J Infect Dis 2007;11:36-9.

5. Graham SM. Nontyphoidal salmonellosis in Africa. Curr Opin Infect Dis 2010;23: 409-14.

6. Gordon MA. Invasive nontyphoidal Salmonella disease: epidemiology, pathogenesis and diagnosis. Curr Opin Infect Dis 2011;24:484-9.

7. Ramos JM, García-Corbeira P, Aguado JM, et al. Classifying extraintestinal nontyphoid Salmonella infections QJM 1996;89:123-6.

8. Dhanoa A, Fatt QK. Non-typhoidal Salmonella bacteraemia: epidemiology, clinical characteristics and its' association with severe immunosuppression. Ann Clin Microbiol Antimicrob 2009;8:15.

9. Cohen JI, Bartlett JA, Corey GR. Extraintestinal manifestations of Salmonella infections. Medicine 1987;66:349-88.

10. Liang JT, Lee PH, Wang SM, Chang KJ. Splenic abscess: a diagnostic pitfall in the emergency department. Am J Emerg Med 1995;13:337-43.

11. Johnson JD, Raff MJ, Drasin GF, et al. Radiology in the diagnosis of splenic abscess. Reviews of Infectious Disesases 1985;7:10-20.

12. Berendes TD, Keijman JM, te Velde LF, Oostenbroek RJ. Splenic abscesses caused by a reptile-associated salmonella infection. Dig Surg 2007;24:397-9. 